\title{
Strategic analysis of environmental and economic potential of Norilsk metallurgical cluster
}

\author{
$O$ Bazhenov $^{1}$, and $A$ Oykher ${ }^{2}$ \\ ${ }^{1}$ Department of Accounting, Analysis and Audit, Ural Federal University named after the first President of Russia B. N. Yeltsin, 19 Mira \\ str., Ekaterinburg, Russia \\ ${ }^{2}$ Department of Machinery Production Organization, Ural Federal University named after the first President of Russia B. N. Yeltsin, 19 \\ Mira str., Ekaterinburg, Russia
}

\begin{abstract}
Strategic significance of Krasnoyarsk territory as well as Arctic Norilsk metallurgical cluster cannot be in contradiction with social sustainability of the region, what is especially important in the context of serious environmental pollution of the addressed constituent entity of the Russian Federation. Thus, the issue on the building a system of strategic analysis and management of environmental-economic potential of Arctic Norilsk metallurgical cluster (ANMC) remains relevant. In preparation of the article we used the methods of systems analysis and synthesis of available information related to the research. Building on existing economic theories, a model of the conception under consideration was introduced, the term 'system of strategic analysis and management of environmental-economic potential of ANMC' was defined and briefly characterized.The results obtained can be used as a methodological framework for the development of strategic documents on several levels: corporate, regional as well as used by the executive bodies for the purpose of justification of the directions chosen for improving socio-environmental-economic sustainability of Krasnoyarsk territory.
\end{abstract}

\section{Introduction}

Norilsk metallurgical cluster is known as one of the most significant industrial centers in Russia. The production capacity of PJSC "MMC Norilsk Nickel" supplies 14\% of global production of nickel, $39 \%$ of palladium, $6 \%$ of cobalt, $11 \%$ of platinum, $12 \%$ of rhodium and $2 \%$ of copper among others. [1] Being the largest municipality situated outside the Arctic Circle, Norilsk remains one of the most environmentally polluted cities in Russia. According to Rosgidromet, "Norilsk has been listed as one of the Russian cities with the highest air pollution levels and is one of the leading in terms of discharges of polluted waste water." [2] All these facts justify a special socio-environmental and economic character of an object of research.

The enterprises which make up a Norilsk metallurgical cluster and represent production areas (a set of connected production areas), have a direct and immediate (through the development of a "synergetic goodwill") impact on the performance of the whole cluster. There is thus a natural wish of management of such organizational-industrial structures to manage the forces of this influence and its direction.

Meanwhile, as any other subject of economic activity, Arctic Norilsk metallurgical cluster (ANMC) is affected by the wide range of environmental-economic factors which may be subdivided into internal factors (internal production and non-production) and external (factors of external micro-environment, external mesoenvironment and external macro-environment).

The issues of a system of strategic analysis and management within a complex corporate system are widely reflected in the modern works of economists So the issues of strategic analysis, as part of corporate governance were considered in the works $[3,4,5,6$, etc. $]$.

Theoretical and applied issues of strategic management were considered $[7,8,9,10$, etc.]. At the same time, cluster structures as an object of research were presented in the following works $[11,12,13,14$, etc.].

However, current approaches to the subject and the object of study require further study of their methodological aspects.

For the purposes of this research a system of strategic analysis of environmental-economic potential of ANMC, in the authors' view, represents a tool which allows, first of all, making an objective assessment of the effects of external and second, internal factors for the purposes of cluster management.

Thus, we consider the necessity of designing a conception of implementation of the system of strategic analysis and management of environmental-economic potential of ANMC to be fully justified.

\footnotetext{
* Corresponding author: o.v.bazhenov@urfu.ru
} 


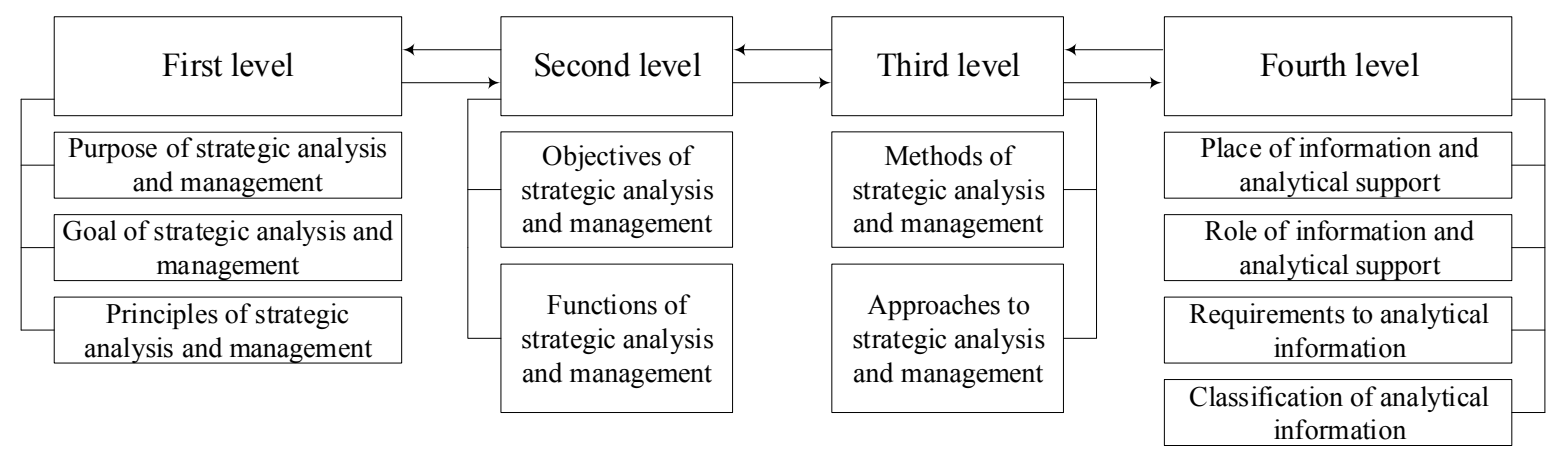

Fig. 1. Organizational and methodological framework for strategic analysis and management of environmental-economic potential of ANMC [15].

\section{Research method}

The elements defining the conception of implementation of the system of strategic analysis and management of environmental-economic potential of ANMC can be structurally presented as follows (Figure 1).

As shown in Figure 1, the organizational and methodological framework for strategic analysis and management of environmental-economic potential of ANMC consists of four levels interacting with one another to establish an integrated.

Strategic analysis and forecasting environmentaleconomic potential of ANMC is aimed at assessment and presentation of future probability data on production and non-production activity of the cluster and its production areas within the context of the current external environment (including environmental component).

Development of the proper information management for general management of ANMC can be defined as the main goal of strategic analysis and forecasting of ANMC activity (including its environmental-economic potential).

Poor quality and absence of analytical data significantly reduces a potential of ANMC management which in turn, may adversely affect results of an enterprise's production activity, destabilize financial flows, and aggravate the financial situation and environmental situation of the territory of an enterprise's dislocation.

Information collected by conducting a strategic analysis and forecasting the activity of ANMC, is intended to become the basis for managerial decisionmaking on the enterprise and some of its production areas as well as to perform as a mechanism for control of processes and operations ongoing in the cluster.

Thus, the strategic analysis and forecasting of economic potential of ANMC is defined as functions of strategic management aimed to provide ANMC managerial staff with consolidated information on the condition of internal (production and non-production) environment, external environment (territorial, intersectoral and state level), as well as on probabilistic state of the environment which is the base for managerial decision-making (both routine and strategic) [16].
In that way, strategic analysis and forecasting environmental-economic potential of ANMC, is defined as a multiplicity of elements providing methodological framework for calculation, assessment, and interpretation and providing comprehensive information for justification and development of managerial decisions.

Levels of the organizational and methodological framework of strategic analysis and forecasting environmental-economic potential of ANMC that are structurally presented in the Figure 1, can be described through goals, objectives, and informational; they are linked in space and time and serve as a basis for formulation of managerial decisions (both routine and strategic).

Implementation of the system of strategic analysis and management of environmental-economic potential of ANMC in particular, allows optimizing the activity of the cluster's and its production areas' (structural subdivisions) monitoring function, which in turn (interacting with the system of management accounting) allows to enhance the validity of the formulated managerial decisions.

\section{Goal and principles of strategic analysis and management}

The goal of conducting a strategic analysis of environmental-economic potential of ANMC will be considered as development of information framework for managerial decisions-making (routine and strategic) which are to be implemented in short-term, medium term and long-term perspective.

Strategic analysis and management of environmentaleconomic potential of ANMC includes many procedures, which demonstrate variability of development during the management process depending on the goals facing their administration.

However, basic methodological principles must remain unchanged regardless of time and implemented management procedures [17]. 


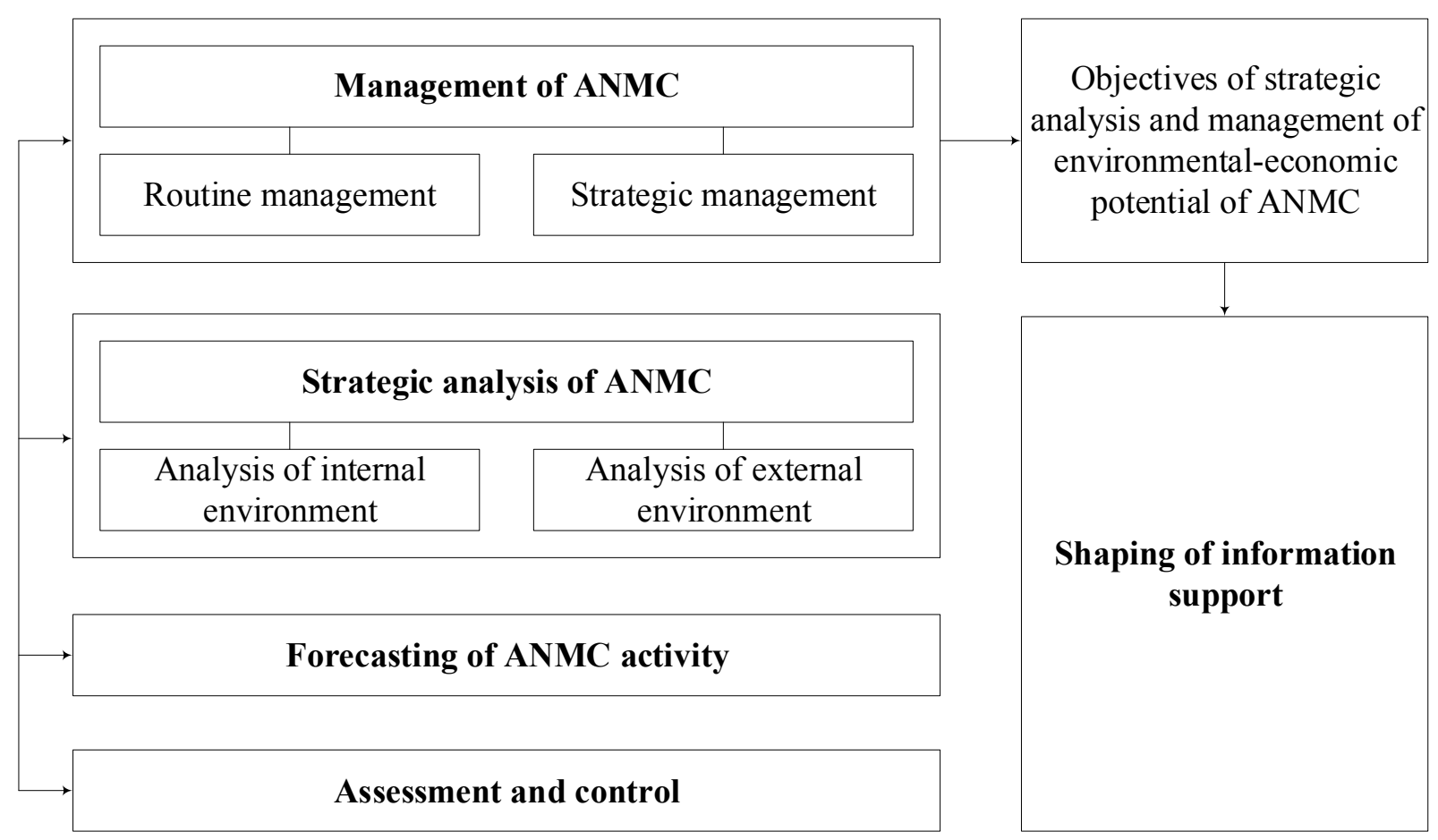

Fig. 2. Overview of the relationship between the management stages and the objectives of strategic analysis and forecasting of environmental-economic potential of ANMC [18].

\section{Objectives and functions of strategic analysis and management}

According to the structure of organizational and methodological framework for strategic analysis and management of environmental-economic potential of ANMC, represented in the Figure 1, its second level is characterized by the objectives and functions of management.

We have formulated the objectives of strategic analysis and management of environmental-economic potential of ANMC based on the essence of the process of strategic analysis and management. In so doing, we took into account the main stages of environmentaleconomic potential of ANMC management (Figure 2). Then we have defined the list of tasks related to each particular stages of the management of environmentaleconomic potential of ANMC.

We have briefly described the model represented in the Figure 1, by formulating the objectives of strategic analysis and forecasting of environmental-economic potential of ANMC on each stage of the cluster management.

For the implementation of the stage "strategic analysis of ANMC", it was necessary to address the challenges ensuring the analysis of both production and non-production internal environment and the analysis of territorial-level, intersectoral-level and state-level external environment.

For the implementation of the stage "forecasting of ANMC activity", it was necessary to address the challenges related to increasing the confidence of development of probability assertion on environmentaleconomic potential of ANMC.

For the implementation of the stage "assessment and control", it was necessary to address the challenges related to providing the monitoring activities, which allow evaluating the extend of achieving the goals assigned by the management of the copper industry enterprise.

Then we represented the objectives of strategic analysis and forecasting environmental-economic potential of ANMC the achievement of those allowed shaping proper information support for implementation of managerial decisions.

Such objectives are assigned and fulfilled on each stage of the management of environmental-economic potential of ANMC and as a rule, they are used as a solution for creating information support which is used by the administration and is aimed at justification and formulating a particular decision. Confidentiality of such information is justified by its strategic meaning and the probability of being used by the rivals for any negative influence on the development of the economic entity.

Thus, the key point of strategic analysis and forecasting is the shaping of information basis, which is critically important for managerial decision-making and evaluation of how they are fulfilled on both levels: on the level of production area ('structural subdivisions') and on the level of entire ANMC, for the benefit of all concerned. 


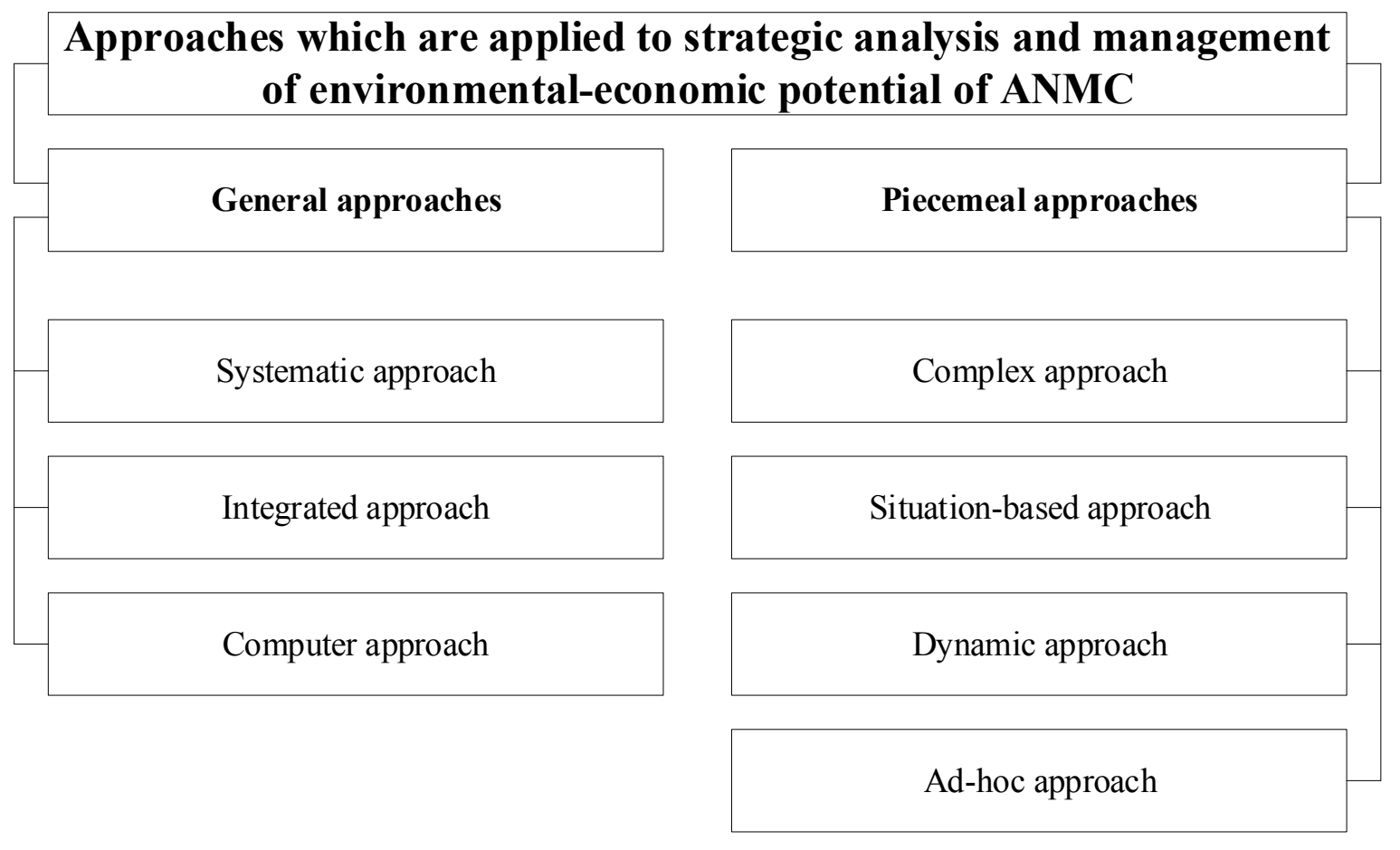

Fig. 3. The structure of approaches which are applicable to strategic analysis and management of environmental-economic potential of ANMC.

\section{Methods and approaches to strategic analysis and management}

According to the structure of organizational and methodological framework for strategic analysis and management of environmental-economic potential of ANMC represented in the Figure 1, it's third level is characterized by the methods of strategic analysis and management and also by the approaches which are applicable to strategic analysis and management.

The approaches which are applicable to strategic analysis and management of environmental-economic potential of ANMC can be structurally represented in the following way (Figure 3).

We have reviewed the structure represented in the Figure 4, in more details.

As a first step, we made a brief description of the general approaches to strategic analysis and management of environmental-economic potential of ANMC.

A systematic approach implied that the system of strategic analysis of environmental-economic potential of ANMC is considered as a part of the system of cluster management, which in its turn is a part of a higher-order system.

An integrated approach implied the usage of the system of strategic analysis and management of environmental-economic potential of ANMC, taking into account a mass of information provided by the system as an element of financial and production activity.

When using the system of strategic analysis and management of environmental-economic potential of ANMC, a complex approach implied the usage of tools for calculations automation provided by specialized software.

On the stage 22 , we have briefly described piecemeal approaches to strategic analysis and management of environmental-economic potential of ANMC.

When using the system of strategic analysis and management, an integrated approach can ensure an interaction with other administrative and securing systems.

A situation-based approach implied concentration of attention on the particular situation when using the system of strategic analysis and management of environmental-economic potential of ANMC.

A dynamic approach allows considering the system of strategic analysis and management of environmentaleconomic potential of ANMC in the dynamics, taking into account the current causality.

An ad-hoc approach implied adapting of the provisions of the methodology of strategic analysis and management of environmental-economic potential of ANMC to specificities of the current internal and external economic environment of the considered economic entity.

Methodological tools of strategic analysis and management of environmental-economic potential of ANMC, are rather various due to integration of methods of several disciplines.

The methods of strategic analysis and management of environmental-economic potential of ANMC combine two most important features: action-related and cognitive-related.

Methodological framework of strategic analysis and management of copper industry enterprises' activity allows providing to the cluster administration the 
information which is important for activity planning hence the choice of the method for strategic analysis directly correlated to the managerial target which should be achieved.

\section{Information and analytical support}

According to the structure of organizational methodological framework of strategic analysis and management of environmental-economic potential of ANMC represented in the Figure 1, its fourth level characterizes information and analytical support.

The main objective of strategic analysis and management of environmental-economic potential of ANMC is the establishment of information basis or information and analytical support for managerial decision-making. In that regard, the function of strategic analysis itself is in particular to provide relevant and regularly updated information support.

The importance of information and analytical support as well as its effectiveness is determined by the information content and the methods which have been used while selection, evaluation and analysis.

Except that the system of strategic analysis and management of environmental-economic potential of ANMC should facilitate speedy access to analytical data and its adaptability to specific character of business activity of a particular enterprise (production area), which is a part of the cluster.

One of distinguishing features of information and analytical support is the necessity to collect strategic information in addition to traditional forms of accounting. For this purpose, when implementing a system of strategic analysis and management of environmental-economic potential of ANMC, it is necessary to use unique software working through the computer technologies and this will reduce the time and labor costs for preparation and processing of all data. Additionally, it is required to use specific, adapted to the condition of economic activity of a particular enterprise (production area) analytical methods, which will shape data for the assessment of a current and forecasted condition of an enterprise and all entire cluster.

\section{Conclusion}

Thus, in this article the authors have considered the organizational and methodological issues of the implementation of the system of strategic analysis and management of environmental-economic potential of ANMC.

During the article preparation the authors' perspective of organizational and methodological framework of strategic analysis and management of environmental-economic potential and the term 'system of strategic analysis and management of environmentaleconomic potential of ANMC has been determined and the functioning of it has been reviewed. In the conclusion the following aspects have been briefly characterized: a goal and principles of strategic analysis and management; objectives and functions of strategic analysis and management; methods and approaches which are used in strategic analysis and information and analytical support of this process.

\section{References}

[1] Annual report of PJSC "MMC Norilsk Nickel" for 2016 [Electronic resource]. Available at: http://www.nornik.ru/assets/files/2017/Godovojotchet-za-2016-god Nornikel(2).pdf.

[2] Ecology of Norilsk [Electronic resource]. Available at: http:/greenologia.ru/ekoproblemy/goroda/norilsk.html.

[3] L. Sanny, M.A. Tuori, L. Simek, Strategic Analysis of the Logistics Industry in Indonesia, Advanced science letters, 24, 12, 9389-9392 (2017).

[4] L. Tian, A.J. Vakharia, Y. Tan, Y. Xu, Marketplace, Reseller, or Hybrid: Strategic Analysis of an Emerging E-Commerce Model, Production and operations management, 27, 8, 1595-1610 (2018).

[5] J. Sanjay, J. Li Krista, Pricing and Product Design for Vice Goods: A Strategic Analysis, Marketing science, 37, 4, 592-610 (2018).

[6] J.R. Zuniga, M. de Jesus Gonzalez Guillen, E.V. Pachecoa, Strategic analysis of the forest productive chain in the region of the Monarch Butterfly Biosphere Reserve, Madera y bosques 24, 1 (2018). UNSP: e2411404.

[7] V. de Lourdes Marques, C. A. Filho, F.N. Pereira, Tools for the Strategic Management of Stakeholders In Civil Construction, Brazilian Journal of Operations \& Production Management, 15, 4, 595-609 (2018).

[8] Ward and Brad 2018, Strategic Management: a Competitive Advantage Approach, Concepts and Cases, Personal Psychology, 71, 4, 638-641.

[9] F.A. Demir, Strategic Management Maturity Model for Innovation, Technology innovation management review, 8, 11, 13-21.

[10] S.K. Ethiraj, A. Gambardella, C.E. Helfat, Theory in strategic management, Strategic management journal, 39, 6 SI, 1529 (2018).

[11] J. Lan, W. Chengjun, Z. Wei, Investigation of the evaluation system of SMEs' industrial cluster management performance based on wireless network development, Eurasip Journal on Wireless Communications and Networking (2019).

[12] S. Anokhin, J. Wincent, V. Parida, N. Chistyakova, P. Oghazi, Industrial clusters, flagship enterprises and regional innovation, Entrepreneurship and Regional Development, 31, 1-2, 104-118 (2019).

[13] N. Pisa, W. Viviers, R. Rossouw, Enhancing Industrial Cluster Formation Through the Realistic Export Opportunities of the TRADEDSM, South African Journal of Economics, 85, 3, 386-404 (2017). 
[14] I.I. Doronina, V.N. Borobov, E.A. Ivanova, E.V. Gorynya, B.M. Zhukov, Agro-industrial clusters as a factor of increasing competitiveness of the region, International Journal of Economics and Financial Issues, 6, 1S, 295-299 (2016).

[15] D.A. Kornilov, Formation of species classification in the field of strategic management strategies, The economic analysis: theory and practice, 21, 24-30 (2007).

[16] A.M. Ilyshev, L.V. Yurieva, The effectiveness of the implementation of the corporate information system at the metallurgical enterprises of the region, Regional economy: theory and practice, $\mathbf{9}$, 2-7 (2005).

[17] L.V. Yurieva, Organizational aspects of strategic management accounting in holding structures, Academic Gazette, 4, 129-135 (2009).

[18] L.V. Yurieva, Formation of information for managing metallurgical enterprise, Urals Science and Industry, 4, 125-123 (2008). 